\title{
La alegría como signo de la nupcialidad en tensión escatológica: Christophe Lebreton - Edith Stein
}

\author{
Cecilia AvenatTi de Palumbo* \\ Universidad Católica Argentina (Argentina) \\ ceciliapalumbo@sion.com \\ ALEJANDRO BERTOLINI** \\ Universidad Católica Argentina (Argentina) \\ alejandrobertolini@gmail.com
}

\begin{abstract}
Resumen
Nuestra hipótesis consiste en considerar la alegría como fruto del dinamismo interpersonal entre Dios y el hombre bajo la figura de la nupcialidad, cuyas notas de reciprocidad, exclusividad, intimidad y fecundidad especifican esta dimensión particular de vida teologal. Al desplegarse en la historia, la nupcialidad adquiere una tensión escatológica pues el diálogo amante de libertades intensifica la presencia recíproca de Dios y el hombre hasta desembocar en una radicalidad que puede conducir al martirio. Tales fueron los casos de dos místicos y mártires contemporáneos, Christophe Lebreton y Edith Stein, cuyos textos testimonian que la alegría se manifiesta como un fruto visible de la entrega definitiva de sus cuerpos.
\end{abstract}

Palabras clave: alegría, nupcialidad, escatología, Christophe Lebreton, Edith Stein, martirio.

\section{Joy as a Sign of a Nuptiality on eschatological tension: Christophe Lebreton - Edith Stein}

\begin{abstract}
Our hypothesis is to consider joy as a result of the interpersonal dynamics between God and man under the figure of marriage, whose traits of reciprocity, exclusivity, intimacy and fecundity give a distinctive specifity to this particular dimension of theological life. As it unfolds in history, nuptiality develops an eschatological tension, as the loving dialogue of freedoms intensifies God and man's mutual presence, leading to a radicality which can usher into martyrdom. Such were the cases of two contemporary mystics and martyrs, Christophe Lebreton and Edith Stein, whose texts testify that joy is manifested as a visible fruit of the final offering of their bodies.
\end{abstract}

Key words: Joy, nuptiality, eschatology, Christophe Lebreton, Edith Stein, martyrdom.

\footnotetext{
* Doctora en Letras por la Facultad de Filosofía y Letras de la Pontificia Universidad Católica Argentina (UCA). Entre sus publicaciones recientes destacan los libros Caminos de espiritu y fuego. Mística, estética, y poesía (2011); y Presencia y ternura. La metáfora nupcial (2014).

** Doctor en Teología por la Universidad Lateranense de Roma. Entre sus libros publicados destaca Empatía y Trinidad en Edith Stein. Fenomenología, teología y ontología en clave relacional (2013); y Odres nuevos para el vino nuevo. Hacia las entrañas de la comunión (2015, en prensa).
} 
Mi alegria: tú. Christhophe Lebreton Espiritu Santo: iJúbilo eterno! Edith Stein

\section{Introducción}

El propósito de este artículo ${ }^{1}$ consiste en considerar la alegría como fruto del dinamismo interpersonal entre Dios y el hombre bajo la figura de la nupcialidad ${ }^{2}$. Al desplegarse en la historia ésta adquiere una tensión escatológica en la que el diálogo de libertades y la presencia recíproca de los amantes puede intensificarse hasta el punto de desembocar en la radicalidad del martirio. Tales fueron los casos de los dos místicos y mártires contemporáneos, Christophe Lebreton (Argelia, 21 de mayo de 1996) y Edith Stein (Auschwitz, 9 de agosto de 1942). Dos contemplativos comprometidos con su pueblo y con el diálogo entre culturas y religiones. Dos figuras en contraste complementario: él monje y poeta, ella carmelita y filósofa. Dos lenguajes que proponemos considerar en el cruce de la imagen simbólica que revela y la razón discursiva que interpreta. Dos modos de habitar y comprender el mundo y la experiencia de Dios, el masculino y el femenino. Dos estilos teológicos no convencionales: el estético y el fenomenológico. En la clave de bóveda, que mantiene la arquitectura de nuestra propuesta, se encuentran la nupcialidad, que es una de las formas del Amor, y la alegría, que en aquélla se origina: en su punto de unión los arcos conservan su particularidad y su tensión paradójica e histórica. En sintonía con el objeto estudiado, ensayamos una escritura interdisciplinaria y en diálogo, donde poesía y teología se integran sin confundirse. El Cuaderno de oración de C. Lebreton, escrito entre agosto de 1993 y marzo de 1996, redactado en clave poética y publicado como El soplo del Don, pautó el necesario recorte de fuentes de la pensadora germana, de cuyo extenso corpus consideramos los escritos espirituales (Stein, 2004a) y filosóficos (Stein, 2004b y 2004c) y autobiográficos (Stein, 2004d) correspondientes al lapso que abarca desde el año 1933 a

\footnotetext{
$1 \quad$ El presente estudio ha sido presentado en el marco de la XXXIII Semana Argentina de la Teología (Lomas de Zamora, julio 2014), cuyo tema congregante ha sido: La caridad y la alegría: paradigmas del evangelio.

2 La opción por «nupcialidad» y no por esponsalidad, tanto en el título como en la estructuración conceptual del trabajo que presentamos, obedece a la perspectiva «escatológica» adoptada en esta investigación. En efecto, como lo demuestra la tradición carmelita, mientras que el uso de esponsalidad ha quedado reservado en el lenguaje místico al desposorio, las «nupcias» del alma llevan en sí la carga propia de lo definitivo. Como nuestro propósito es proponer la alegría como signo de la nupcialidad «en tensión escatológica», juzgamos más apropiado el uso de un término que permitiera expresar la concentración en lo definitivo.
} 
1942, dado que en ellos ambos autores despliegan con mayor claridad su comprensión de la dimensión esponsal de la vida teologal. A esta secuencia responde la estructura de nuestra exposición: primero, la nupcialidad como forma originaria del Amor, luego, la alegría como uno de sus frutos, y, finalmente, el clímax del testimonio martirial que, en vistas del compromiso de ambos con sus respectivos pueblos, proponemos interpretar en clave histórica y escatológica.

\section{La nupcialidad como forma originaria del Amor}

En el centro de la Sagrada Escritura se canta al Amor nupcial, que es libre y fiel, como el pascual y como el escatológico del acto final ${ }^{3}$. El Amor vivido en clave de nupcialidad fue la fuente de la experiencia martirial de C. Lebreton y de E. Stein. En ambos corpus textuales podemos reconocer las notas de reciprocidad, exclusividad, intimidad y fecundidad que especifican esta dimensión particular de vida teologal (Olivera, 2008), las cuales, aunque con diferente estilo, se presentan con compartida intensidad vital. En esta primera parte mostraremos que la nupcialidad aparece en ellos como forma originaria del Amor de Dios hecho carne en sus vidas y escrituras. Entre los últimos manuscritos de C. Lebreton, Bernardo Olivera recoge en uno de sus libros algunos poemas cuyo expreso tono nupcial constituye el punto de partida de la lectura que aquí proponemos, el primero de los cuales dice así:

Como el libro delante de mí

el año 1996 está abierto y en la noche:

tu voz (en el corazón del Libro)

la tierra desposada escucha que le dicen

hete aquí eres hermosa amiga mía

$[\ldots]$

un día de este año hazme la gracia tú

Amado de decirme verdaderamente

entro en mi jardín

recojo como

bebo

toda tu vida

hazme entonces la gracia de donarte yo

sin medida mis amores (Olivera, 2008: 195-196).

Estos son los ejes sobre los que Ricoeur (2001) propone realizar como una lectura teológica actualizada del Cantar bíblico. 
Como en el Cantar bíblico, también aquí al discurso oracional le corresponde la primera y segunda persona gramatical. Esta opción por un lenguaje directo signa el estilo lírico de C. Lebreton, en el que se destaca primero la nota de reciprocidad intersubjetiva — «delante de mí», «tu voz»-, la cual abre el camino a la intensificación que conduce a la segunda y tercera nota de intimidad y exclusividad del deseo de unión: «tú / Amado», «entro en mi jardín», la cual se consuma eucarísticamente en la acción de los verbos «recojo / tomo / bebo / toda tu vida», para alcanzar finalmente la fecundidad en la entrega «sin medida».

¿Dónde comenzó esta historia? ¿Cómo llega este monje a una tal transcripción en un lenguaje cuya transparencia perfora la imaginación del oyente? Según él mismo lo narra, la experiencia originaria aconteció en sus tiempos de estudiante, cuando la relación entre Dios y él quedó fundada sobre un «te amo» recíproco:

Tu querer: de una amplitud infinita.

En el fondo, vuelvo siempre a este te amo dicho un día, en Tours.... Y en esa expresión se centra mi vida: estoy sobrepasado, desbordado, excedido. Vas a decirme, Amor, por Fin lo que quieres decir en mi miseria amante que ha quedado ahí, en este punto de infinita pobreza, cuando yo he dicho a otro te $\mathrm{amo}^{4}$ (Lebreton, 2002: 119).

La libertad y fidelidad, que Ricoeur (2001) destaca como dos signos del amor nupcial del Cantar bíblico, introducen en el seno del vínculo entre el Amado y el amante el dinamismo del vaciamiento y la entrega, indicados aquí a través del contraste entre «la amplitud infinita» y la «infinita pobreza» que es «miseria amante»: dos notas perijoréticas que el ser humano no puede sino experimentar como exceso y desborde. La expresión «te amo», repetida en bastardilla una y otra vez en el diario (hasta veinticinco hemos contado) constituye el núcleo personal inviolable de C. Lebreton, quien hace explícita su potencia y fecundidad cristológica, cuando dice: «Ese secreto llama a mi cuerpo: para ofrecerlo en ofrenda. A este precio, puede derramarse, entregarse: secreto de tu yo te amo para la multitud»(Lebreton, 2002: 76). De ahí que su vida teologal entera

4 En otro pasaje vuelve sobre la misma experiencia: «Dios: tú deliberadamente. A la hora de Nombrarte, nuestro lenguaje es siempre impuro. Esa fue la experiencia —en mi cuarto de estudiante vigilante en Tours... - ni una sola imagen de Dios. Pero este te amo desgarrando mi carne: acto de confianza perdida. [...] ¿Imagen de Dios en estas circunstancias? Deseo de ver. Y la vida como una purificación de la mirada. En mi carne: VERTE» (Lebreton, 2002: 151). 
pueda ser interpretada, con legitimidad, desde este núcleo nupcial. Así, por ejemplo:

Conviene que me deje moldear por la acción de la Cruz: tu te amo con amor loco. [...]

Es tu yo te amo que me atrae a la reciprocidad del Don.

Tu libertad, Jesús, es la de pasar: a donde yo voy,

después,

estamos los dos allí: es cuestión de seguirte.

$[\ldots]$

Creer es sintonizar con tu retorno al Padre. Este consentimiento abre mi corazón al Don que me hace permanecer donde tú vas, allá donde tu "Yo soy" es te amo, comunicándome abiertamente al Padre, Abbá.

$[\ldots]$

Aquí en mí - tan lejos y tan cerca:

En Ti tengo acceso a mi propio yo, entregado al amor con que eres amado, cuando alguien me ama-

y cómo decir te amo si no es gracias a tu mismo Soplo

vendremos a él

el Padre y yo.

$[\ldots]$

Padre, Abbá, maravilla de tu gracia, yo puedo darme a ti

sí, en Jesús tu Hijo: entregarme del todo

es un via crucis, lo advierto: hay que caminar: enteramente entregado (al

Espíritu)

niño entre tus manos

sí, voy a ti

ya vengo (Lebreton, 2002: 86, 91, 83, 200).

Desde el punto de vista estético teológico es en la forma donde se patentiza de modo inmediato el fondo, y, no más allá ni fuera de ella es de donde brota la luz. Por tanto, también aquí, en esta forma poética atravesada por el dinamismo de la acción verbal es donde el núcleo nupcial se manifiesta. En consecuencia, interdisciplinariamente considerado ${ }^{5}$, del lenguaje poético nupcial inferimos, primero, el carácter dinámico interpersonal de la relación unitiva entre Dios y el hombre expresado en la elección verbal del «te amo» como signo distintivo de su estilo, y, segundo, la referencialidad al origen trinitario del Amor, dos notas que

5 Para el método interdisciplinario de diálogo entre literatura, estética y teología, hemos tenido en cuenta los resultados de investigaciones anteriores que hemos confrontado y fijado en publicaciones (Avenatti de Palumbo, 2006; 2010; Bertolini 2013; 2014). 
encontramos también en la nupcialidad fenomenológica y trinitaria de Edith Stein.

De estilo tan diverso como convergente, la filósofa carmelita encuentra en la nupcialidad no solo una forma más de referirse al amor divino sino una clave englobante de su pensamiento que hunde sus raíces en su fenomenología de la intersubjetividad, configura la misma identidad divina y se proyecta sobre la creación, la redención y la consumación del hombre como verdadero núcleo significante.

La matriz de la cual parte es la empatía. Sin ella el individuo no es persona. Esta vivencia sui generis logra enlazar la alteridad y la identidad en un movimiento elíptico de salida de sí, inmersión en el otro y retorno a la propia mismidad, ahora habitada por la experiencia ajena. Lo curioso es que luego de describir esencialmente este mecanismo, en tiempos de agnosticismo confeso, sentencia lo siguiente:

Así aparece la experiencia que un yo en general tiene de otro yo en general. Así aprehende el hombre la vida anímica de su prójimo, pero así aprehende también, como creyente, el amor, la cólera el mandamiento de su Dios, y no de modo diferente puede Dios aprehender la vida del hombre (Stein, 2004c: 88).

E. Stein trabaja todavía sobre un Dios cuya existencia es hipotética, lo que hace aún más sugerente la propuesta. Su razonamiento podría parafrasearse así: de existir un Dios, éste conocería y se dejaría conocer por la empatía. Las relaciones con un Dios empático harán del dinamismo personal intersubjetivo el quicio de su experiencia religiosa, que rápidamente devendrá en esponsalidad.

Al convertirse al cristianismo, E. Stein contempla el misterio con su inteligencia punzante y lee directamente de las fuentes tanto las mejores síntesis teológicas de su tiempo como los clásicos autores de referencia indiscutida (Tomás de Aquino, Agustín de Hipona, Buenaventura di Bagnoreggio, Duns Scoto), de los cuales toma elementos que explican la lograda articulación de lo que sigue. Pero es la filiación espiritual del Carmelo, con Teresa y Juan de la Cruz como figuras señeras, la que opera como factor decisivo de la formación de un pensamiento estructurado en torno a la nupcialidad no sólo a nivel místico espiritual sino también y genuinamente, teológico y ontológico. A tal punto esto es así que se puede afirmar sin ambages que el mismo diseño de su cosmovisión creyente puede ser evidenciado desde esta clave de bóveda.

De acuerdo con lo cual, en su pensamiento es posible distinguir tres registros de esta clave nupcial: uno cosmológico, otro cristológicotrinitario y un tercero antropológico-teologal, todos profundamente en- 
trelazados. Imposible de retratarlos en detalle por razones de espacio, se presentan bien imbricados en esta cita panorámica y sintética:

La relación del alma con Dios tal como Dios la previó desde la eternidad como meta de su creación, apenas cabe caracterizarla de un modo más atinado que el de la unión esponsal. Al revés: lo dicho sobre el sentido de la relación esponsal, en ninguna otra parte se cumple tan propia y perfectamente como en la unión de amor de Dios con el alma. Cuando se ha comprendido esto una vez, entonces la imagen y la cosa se intercambian sus papeles: la esponsalidad de Dios es reconocida como la esponsalidad propia y original y toda relación esponsal humana aparece como imagen imperfecta de aquel arquetipo (Stein, 2004b: 414).

Según lo dicho, la creación entera tiene por objeto la íntima compenetración entre los dos amantes: el alma y Dios. Habrá que pensarlo todo desde estas nupcias arquetípicas - cosmología, cristología, soteriología, escatología, gracia, antropología, iglesia, sacramentos- en vistas a lograr una síntesis tan compleja como fascinante. Ello significa, según su típica perspectiva antropológica, que estamos hechos para la intimidad fecunda, exclusiva y recíproca con la divinidad, y al servicio de esta relación plenificante está la obra entera de la salvación. Tal objeto no es sino la participación de la nupcialidad intratrinitaria que en Dios resulta excesiva y desbordante:

El amor desbordante con el que el Padre engendra al Hijo y le da su esencia, y con el que el Hijo recibe esta esencia y se la devuelve al Padre, el amor en el que el Padre y el Hijo son una misma cosa y que ambos aspiran simultáneamente como su espíritu. De esta manera el alma vive de la gracia por el Espíritu Santo, ama en Él al Padre con el Amor del Hijo y al Hijo con el Amor del Padre (Stein, 2004a: 349).

Stein se apropia de forma creativa de la doctrina de su maestro abulense y logra situar en este clímax místico la verdadera consumación de la existencia humana: «Juan mismo describe el matrimonio espiritual como una entrega libérrima de Dios al alma y del alma a Dios, y atribuye tal poder al alma que dice que es no sólo dueña de sí misma, sino también de Dios» (Stein 2004a: 344). Afirmación osada que muestra el «empoderamiento» que logra lo humano en esta libre y recíproca entrega, como contracara del vaciamiento personal. ¿Puede el hombre pretender algo más? La comunión de bienes es total, porque el desasimiento es radical:

entre Dios y el alma está actualmente formado un amor recíproco en conformidad con la unión y entrega matrimonial, en los que bienes de entram- 
bos, que son la divina esencia, poseyéndolos cada uno libremente por razón de la entrega voluntaria del uno al otro, los poseen entrambos juntos (Stein, 2004a: 121).

Sin embargo, así presentado este final de proceso parece describir al «alma» desgajada de la historia y de la comunión humana. Es sabida la sospecha que pesa sobre la mística carmelitana: la de un intimismo intramuros, ahistórico y dualista, que hace de esta exquisita nupcialidad con Dios un estadio demasiado caro a nuestro tiempo. El atractivo de estos místicos contemporáneos - tanto Christophe como Edith- es que piensan y viven profundamente entrelazados con la historia y el lugar donde les toca abrazar al Amado, pues es allí donde el Amado les sale al encuentro. Por eso, cabe preguntar ¿cómo se llega a tal unión? El entero plan de salvación se despliega para explicarlo, aunque aquí podamos solo exponerlo en sus rasgos esenciales.

«Dios en nosotros y nosotros en él, en esto consiste nuestra participación en el Reino de Dios, cuyo fundamento ha puesto el mismo misterio de la encarnación» (Stein, 2004 a: 485). Como podemos apreciar, en Stein la encarnación del $\mathrm{Hijo}^{6}$ tiene sentido de fundamento para una plenitud posterior. Bien podemos leerla como desposorio con aquella humanidad que a través de la pascua habrá de integrarse en la comunión trinitaria. La tensión inaugurada con la encarnación ${ }^{7}$ lleva por sí misma a la resolución del drama de la existencia en la redención entendida siempre en clave de expiación vicaria, pero con un co-protagonismo inusitado de la humanidad, que la misma Stein sabrá interpretar histórica y personalmente.

¿Pero qué dolor ardiente puede medirse con el de la pasión del Hombre-Dios quien durante toda su vida poseyó la visión beatífica de Dios, hasta que por propia y libre decisión se privó de este gozo la noche de Getsemaní? (...) Sólo él, el Único que lo ha experimentado, puede dar a gustar algo de ello a los que él ha elegido para eso, en la confidencia de la unión esponsal (Stein, 2004a: 426-427).

6 Tal comprensión es llamativamente cercana a la propuesta de Rahner pues según ella, la encarnación de algún modo comienza con la creación de cada hombre. Es más: llegará a hablar de un Logos hecho mundo en profunda correspondencia con el Logos hecho carne (Stein, 2004b: 1108-1109).

7 «En la cruz tenemos el signo de la pasión y muerte de Cristo, y de todo lo que está ligado a ello como su causa y clave de explicación. Por un lado, hay que pensar en el fruto de la muerte en la cruz: la redención. Pero aquí hay que señalar que la Encarnación está con ella estrechamente relacionada como condición de la Pasión y muerte redentoras» (Stein, 2004a: 426-427). 
La redención figura entonces como una concesión de aquella misión propia del Esposo que se transfiere a la esposa en el intercambio existencial, pero que acontece en las mismas entrañas de la historia.

El mundo está en llamas, ¿te sientes impulsada a apagarlas? Mira la cruz. Desde el corazón abierto brota la sangre del Redentor (...) Si estás esponsalmente unida a él en el fiel cumplimiento de tus santos votos, es tu sangre su sangre preciosa. Unida a él eres omnipresente como él. Tú no puedes ayudar como el médico, la enfermera o el sacerdote aquí o allí. En el poder de la cruz puedes estar en todos los frentes, en todos los lugares de aflicción, a todas partes te llevará tu amor misericordioso, el amor del corazón divino que en todas partes derrama su preciosísima sangre, sangre que alivia, santifica y salva (Stein, 2004a: 634).

Para la santa carmelita, la esponsalidad articula toda la propia cosmovisión creyente desde la clave antropológica: una auténtica perijóresis teándrica de realización progresiva que le abre paso hacia el fondo de sí misma recorriendo la noche oscura de la historia como participación en el abandono de la cruz. Atravesada la negación de sí, el alma es transformada para el matrimonio espiritual, en el que toma parte la Trinidad entera. Tal es el amor para el que el alma fue creada y redimida.

\section{La alegría como fruto de la fecundidad nupcial}

«Mi alegría: tú» (Lebreton, 2002: 39). La potencia expresiva de la palabra poética ha sido llevada en este verso a una concentración extrema en la que podemos, sin embargo, reconocer con nitidez el itinerario vital de C. Lebreton. Con razón afirmaba Balthasar que «la experiencia estética es la unidad de la suprema concreción posible de la forma individual y de la máxima universalidad de su significado o de la epifanía del misterio del ser en ella» (Balthasar, 1985: 213) Si analizamos lexical y literariamente esta lograda expresión poética, advertimos que los pronombres personales «mi» $\mathrm{y}$ «tú » sostienen la arquitectura del verso como dos columnas que no se funden ni confunden. Siguiendo el trazado de esta figura, podemos observar que el punto de unión de ambos polos se da justamente en el sustantivo «alegría», que actúa como visibilización del encuentro interior, el que acontece en la bodega, en la «intimidad», a resguardo de miradas ajenas y curiosas cuya presencia perturbaría la «exclusividad» de la entrega «recíproca». Más aún, la alegría puede ser interpretada como signo de la fecundidad nupcial, que ontológicamente se encontraría vinculada a los otros tres signos ya mencionados, pues de ellos brota. En estas notas nupciales reconocemos asimismo los rasgos peculiares de la 
mística cristiana de matriz bíblica y litúrgica: el «tú» indica la responsividad a la siempre previa palabra-acto de Dios; el «mi» refiere a la identidad de un yo en disponibilidad y obediencia; la «alegría» al exceso del don entregado y recibido, es decir, el intercambio de amor como única medida de juicio (Balthasar, 2008).

No podemos dejar de señalar, además, un aspecto formal que ha llamado nuestra atención desde la primera lectura: la insistencia en reforzar la separación mediante el uso recurrente de los dos puntos, que se reitera en todo el cuaderno dando lugar a una constante del estilo poético de C. Lebreton, lo cual nos ha dado qué pensar. Recordemos que desde el punto de vista lingüístico, los dos puntos constituyen una pausa menor que la exigida por el punto cuya finalidad es llamar la atención sobre lo que sigue, que siempre está en estrecha relación con el texto precedente. Entre sus varias funciones, C. Lebreton elige la que, mediante la elipsis del nexo, indica relaciones de causa, consecuencia y síntesis, a lo cual le agrega un valor poético propio. En efecto, si la separación ya había sido señalada por los pronombres posesivo y personal, «mi» y «tú», ¿para qué destacarla nuevamente? ¿Para acentuarla o para decir algo nuevo? ¿No habrá hecho el poeta un uso «metafórico» del signo de puntuación a fin de expresar mediante este recurso el carácter inefable de la simultaneidad del hiato y la unión en el amor nupcial? Creemos que sí, que la recurrencia al signo de separación remite, por un lado, al hiato existencial entre la criatura y el Creador, pero a su vez, también, al hecho de que la unión nupcial no acontece sino en la simultaneidad de vacío y plenitud, distancia y presencia, abandono y acogida, que no son sino formas trinitarias del amor. El uso de este recurso en otros pasajes del diario poético confirmaría nuestra hipótesis. Sólo mencionaremos algunos en los que hemos advertido expreso sentido nupcial en el dinamismo de unión y separación considerado:

Ya hay en este cuaderno regalo de día de fiesta, lo hay: eres tú.

Tu alegría dada es como

acoger al huésped

mantener afinado el tono justo

de humildad y de ritmo: Tú.

Tu Día: para nosotros, para nuestra alegría. Tu alegría plena en nosotros.

Hoy experimento, en el fondo de mi ser, la dicha de estar en mí: Tú, el Amado del Amor.

Mirada que me da a luz: tú quieres mi alegría, que viva feliz y libre en el Don (Lebreton, 2002: 29). 
La forma bella se entrega porque a su vez ha sido ella misma entregada. En el mostrarse mismo radica su indefensión y su defensa: está allí para ser contemplada y amada, pero sólo la percibe el corazón puro, los ojos que purificados de su tendencia egocéntrica pueden salir de sí y ver la luz que la forma del otro irradia. La percepción de esta hermosura produce alegría en el corazón del hombre, como lo indicaba la Gaudium et Spes 62 (Avenatti de Palumbo, 2006): este es el núcleo de la experiencia estético teológica de C. Lebreton. Del verbo griego jáiro (alegrarse) procede járis (gracia, alegría) (Balthasar, 1992), lo cual demostraría ya a nivel lingüístico lo que la teología sostiene, a saber: que es la donación excesiva del Tú divino la que provoca la alegría profunda del hombre, que es la desmedida del Amor que se vacía de sí para entregarse al otro la que hace posible la que consumación de la unión. Así lo expresa C. Lebreton: «Saboreo la inmensa alegría -inmerecida del todo- de ser tu discípulo amado. Junto a María encuentro la calma que proviene de mi origen pascual: una inmersión en el Amor trinitario y la exigencia del Don» (Lebreton, 2002: 171).

Desde esta clave trinitaria podemos establecer correspondencias con otros pasajes del Cuaderno en los que el hiato se vincula con la aspiración. En efecto, los dos puntos separan pero también nos hacen detener para que podamos respirar y en consecuencia permiten poéticamente entrar en sintonía con la aspiración del hombre por el Tú divino, aspiración de amor que es aquí el contenido de la alegría:

Dame de beber: de ti. Con la boca bien abierta: aspiro.

Tus palabras son para mí (para nosotros): soplo y vida.

Recibo la misión de ser fuente: Tú en mí, que brota hasta la Vida eterna.

Misión de respirar (Lebreton, 2002: 62).

La vinculación entre belleza y alegría, entre belleza y gracia responde a su referencialidad al Don. En la Trinidad inmanente es el Espíritu de Amor el que aspira al Hijo y, como osadamente lo señaló el doctor místico san Juan de la Cruz, el ser humano participa en la Trinidad económica de la misma aspiración de amor. Junto a la metáfora sanjuanista de «la llama de amor» del Esposo, «que es el Espíritu Santo» (Juan de la Cruz, 2004: 955, 1135), coloca Lebreton la metáfora de la aspiración que es obrada por la «abertura» de la Cruz por donde llega el Don al hombre:

Camino que se abre. Estoy agarrado por el acontecimiento: aspirado por tu libertad de Hijo.

Ábrete. La Abertura sólo puede ser recibida de alguien cuyo ser total me llega a lo más profundo, despertando mi deseo. [...] 
No faltar a la Abertura por donde se precipita el Don, y me aspira hasta la Cruz donde tú, Jesús, mantienes abierta la vida.

Seguirte es entrar en tu PASCUA, empeñarse en la Abertura. Seguir a Dios, caminar en tu Presencia. Adherir al Don (Lebreton, 2002: 132, 133, 139).

Es precisamente en el dinamismo pascual del Don-Abertura-Cruz que la alegría adquiere tensión escatológica, dando paso así a la acción pneumatológica del Soplo del Espíritu.

Esta asociación entre Alegría y Espíritu señala una sintonía profunda con la mártir del Carmelo. En su Novena de Pentecostés, y luego de haber cantado al obrar creador del Aspirado Aspirante, Edith nos sorprende con la última estrofa de su composición:
¿Eres tú el dulce canto del amor y del santo recato
que eternamente suena en torno al trono de la Trinidad
y que desposa consigo los sonidos puros de todos los seres?
La armonía que aúna los miembros con la Cabeza
donde cada uno encuentra feliz el sentido secreto de su ser,
y jubilante irradia/ libremente desprendido en tu fluir:
¡Espíritu Santo - Júbilo eterno! (Stein, 2004a: 775).

Siguiendo con la lógica de la personalización del gozo en la presencia personal del Amado, Stein condensa en pocos versos los rasgos cosmológicos y soteriológicos del Espíritu Santo dándole sobre todo un marco eucológico (dulce canto de amor que suena en torno a la Trinidad): una circularidad de alabanza en la que la creación entera participa, en Él, de la liturgia eterna intradivina. La tercera persona de la Trinidad desposa consigo lo diverso y lo unifica en un mismo flujo armónico: el de la entrega recíproca entre el Padre y el Hijo. La clave nupcial de todo el obrar ad extra de Dios parece encontrar en Él mismo su agente, porque - permítasenos la osadía-: Él sería en persona esta mutua inmanencia dinámica, este estar uno en el otro - hacia el otro, desde el otro y en torno al otro- que en la intimidad divina se celebra desde siempre. Ya su maestro Juan de la Cruz había apelado a la nupcialidad intratrinitaria con la imagen inédita del romance In principio erat Verbum: «como amado en el amante uno en otro residía» (Juan de la Cruz, 2004: 65), refiriéndose a la mismísima perijóresis intratrinitaria antes de la creación del mundo. Por tanto: el que genera la recíproca inmanencia en Dios es también quien aspira y desposa a la creación hacia y en el mismo Esposo, quien la atrae en pascual pasaje de amor hacia la plenitud de sí misma en Él. Y es en este proceso todavía in fieri que cada uno encuentra el gozo que teje simultáneamente el despojo de sí y el ensamble en el todo en tensión de 
alabanza: pues el que Aspira es no solo la misma Nupcialidad intratrinitaria, sino el «Júbilo Eterno», la Alegría del Don en tensión comunional permanente, en continuo y personalísimo desborde kenótico y agápico.

Bajo el influjo del Espíritu, la tensión escatológica se revela tensión de alabanza porque en Él se entra en el místico juego de aspiración activa y pasiva con el Amado. La Alegría es proporcional al grado de compenetración con el Crucificado Resucitado; por eso «el Espíritu y la esposa dicen: Ven» (Ap 22,17).

\section{La alegría en tensión escatológica: contexto histórico y martirio}

Christophe Lebreton y Edith Stein se cruzan en la tensión escatológica de la alegría nupcial con la que viven su inserción histórica. «Ven. Nos vamos para nuestro pueblo (Edith Stein)» (Lebreton, 2002: 51). Ir hacia el pueblo es ir hacia el Amado porque en sentido estricto, el cuerpo de Cristo en dimensión social hay que entenderlo no referido a la Iglesia sino a la humanidad sin más ${ }^{8}$. El misterio pascual continúa activo en el pueblo crucificado: «Bajo la cruz entiendo el destino del Pueblo de Dios que por entonces ya comenzaba a anunciarse... Hoy comprendo mejor lo que significa estar desposada con el Señor bajo el signo de la Cruz» (Stein, 2004d: 1291). Esta confidencia de Edith a su amiga Petra Brunning muestra el grado autoconciencia e implicación en la tensión hacia un plus presente en la realidad de un desposorio que exige intimidad total en la entrega recíproca de los cuerpos, bajo la forma pascual y kenótica propia de la cruz en la noche oscura del tiempo que vivía.

La misma cita que animó el párrafo anterior aparece en el Cuaderno de oración de $\mathrm{C}$. Lebreton y nos pone en camino hacia el encuentro de ambos en una experiencia martirial que presenta importantes puntos en común, bajo la imagen de la viña. Así expresa el monje el contexto histórico en clave nupcial:

La misión del pueblo que sufre abre de par en par la casa de oración [se refiere al monasterio]. [...] La Iglesia como el pueblo argelino: tiene el alma atravesada por una espada. [...]

Señor Jesús, tu amigo -el país a quien amas- está enfermo. Y nosotros, yo también, heridos de amor. [...] Ante la muerte decidida, este lugar resiste y permanece: lugar de la convivencia esencial, del diálogo, del compartir.

8 «Tal vez no sea demasiado aventurado decir que en cierto sentido la creación del primer hombre debe ser considerada ya como un comienzo de la encarnación de Cristo. [...] Toda la humanidad es la humanidad de Cristo... y la humanidad comienza su existencia en el primer hombre [...] La humanidad es entonces, el cuerpo de Cristo en sentido estricto» (Stein 2004b: 1108-1109). 
Algo está pasando ahí: una mujer que entra y realiza un acto de locura: su amor profesado allí mismo ante todos. Amor del Amado.

Eso hace en Bologhine el hombre que recoge al policía herido por un terrorista y tendido en medio de la carretera, y lo sube a su coche para llevarlo al hospital -salvándole la vida.

Y asesinado una semana después. [...]

Lo que hace resistir, es estar aferrado a Jesús, comulgar con el Don en Acto: resolución de Amor. [...]

Cómo no estar desposeídos por tanta angustia en torno. Y por la Alegría: extraña, salvaje, libre: tu alegría, aquí, inculturada. ¡Vamos! Hoy: a la VIÑA (Lebreton, 2002: 45, 92, 94, 104).

La viña del Cantar leída en clave de intertextualidad evangélica sitúa a la alegría en el espacio político de violencia, muerte y mal social argelino, que es el que finalmente provocará su muerte. La percepción y consecuente expresión de la alegría queda transmutada, razón por la cual el poeta orante elige los inusuales adjetivos de «extraña», «salvaje» e «inculturada», para referirse a ella. La nupcialidad se sitúa en el centro de una acción pascual en la que todo este su pueblo de adopción, africano y musulmán, se halla asumido y comprometido: el pueblo es esta «viña», que se concentra poéticamente en el adverbio de lugar «aquí». En efecto, el Tú del Esposo realiza su acción en un lugar concreto: «aquí, en Argelia» (Lebreton, 2002: 184). De este modo, la alegría, como leit motiv poético y teológico, va paulatinamente ascendiendo en intensidad dramática, a tal punto que a medida que aumenta la violencia exterior crece el deseo nupcial:

Tú mi alegría, mi grito,

oh entrégate en mí. [...]

Sí esto me centra en un único deseo (tanto otros le hacen guerra... hasta el deseo de terminar).

Habitar en Tibhirine - habitar en tus huertos: unido a Ti que vienes (Lebreton, 2002: 209).

También Stein recurre a la metáfora de la viña como expresión de la nupcialidad:

Déjanos, Amado mío,

ir a la viña.

Ven, por la mañana temprano

queremos quedar en silencio;

si la viña florece,

si da fruto,

si la vida está candente, 
la vid permanece fresca (Stein, 2004a: 767).

El lugar del encuentro nupcial también en este poema de E. Stein es la viña, una metáfora de la embriaguez a la vez que de la muerte: la flor, el fruto y la vida suceden si el Esposo da sentido a la existencia humana. La nupcialidad es vista, por ella, como la acción operante de Dios en la oscuridad de la tierra:

Lo que Dios obra en nuestras almas durante las horas de oración interior está escondido a la mirada de los hombres. Es gracia tras gracia. Y todas las otras horas de la vida son una constante acción de gracias por ello. [...] quizás un martirio silencioso a lo largo de toda la vida y del cual nadie tiene noticia, y a la vez una fuente de paz profunda y de una alegría que nace del corazón y un manantial de gracia que brota en la tierra-, sin que nosotras sepamos adonde se dirige y sin que los hombres que la reciben sepan de dónde viene (Stein, 2004d: 564-565).

Es de notar aquí un clásico sentido apostólico por desborde, propio de la vida contemplativa, pero esta vez asociado de forma pacífica a la gratitud que alaba en forma de martirio incruento. Como si alabanza y martirio se identificaran en un mismo movimiento desposeído y gozoso hacia los brazos del Amor, pero con profunda incidencia en el cuerpo en que se está insertado. Algo análogo encontramos en el monje francés, en quién la conciencia del compromiso social de la vida de oración y de la escritura poética es significativa. El «aquí» de la nupcialidad está claramente referido a la situación histórica:

Asesinatos en Argelia. Se suman a tantos otros

Este cuaderno no puede quedar al abrigo de esta violencia. Ella me atraviesa. $[\ldots]$

En medio de nosotros, aquí y en Tibhirine, algo está aconteciendo. Algo está por hacer, que tiene por autor y firmante al Verbo hecho carne: tú, Jesús resucitado, Señor mío. [...]

Mi deseo es quedar aquí, quiero arraigar donde estoy. El reino de Dios está aquí y ahora y no en otra parte. [...]

¡Vamos! ¡El tiempo apura: rápido!

La historia espera de nosotros tu Beso de paz.[...]

Por el momento, se trata

de quedarse y vivir aquí

hasta que vengas: AMOR (Lebreton, 2002: 28, 193, 201, 38, 50).

Sugerente mención del carácter de encarnado del Verbo que gesta lo latente, lo que bulle en el silencio expectante de la noche. Es el Verbo 
encarnado - Señor Resucitado: es el que pasó por la criba de la cruz y ahora viene con su cuerpo pneumático y transfigurado al encuentro. Lo provisorio, incompleto y todavía caduco se dispone al beso y a la intimidad transformante y liberadora con el Cordero degollado y de pie:

He aquí el cordero, está aquí. Pronto: las bodas.

En el hueco de una cashabia -más fuerte que el homicidio-

está Él: ha nacido en medio de nosotros

para ser ofrecido

en nuestras vidas.

$[\ldots]$

¿Dónde está el cordero para la subida?

El cordero y encima de él la paloma vienen

a librarme de lo que tengo de bestial disputándose en mi vida (Lebreton, 2002: 246).

La conciencia aguda de la presencia del Cordero y del Espíritu (la paloma sobre él) tiende a disponer a la entrega pues parece desdibujarse la distancia entre Él y Christophe, sobre la clásica valencia pendular de la imagen paulina de Iglesia, que es tanto Esposa -otra distinta del Amadocomo cuerpo de Cristo Cabeza - parte suya, que continúa la pasión en su prolongación histórica (Col 1,24). Y una vez más: la noción de cuerpo articulando la entrega final. Por su lado, Stein llega a la misma lectura en la contemplación del misterio eucarístico como álgida y luminosa condensación del sentido de lo que está por vivirse:

Tú dijiste: 'Todo está cumplido'; e inclinaste la cabeza en silencio. [...]

Cada mañana el repicar de las campanas llama

por todas las calles e invita al banquete de bodas. [...]

Con alegría oculta [ellos] siguen la llamada [...].

Ahí fuera se desencadenan tormentas y luchas horrorosas.

El abismo ha sido abierto,

y los animales han subido del profundo

y combaten poderosamente

para el dominio del gran dragón.

Pero aquí hay paz, aquí el Trono del Cordero en la tierra. [...]

¿Cuándo, Señor, cuándo será ese día?

Mi Señor y mi Dios, escondido bajo la forma de pan

¿Cuándo te manifestarás en tu gloria?

En dolores de parto se halla el mundo,

La esposa aguarda:

¡Ven pronto! (Stein, 2004a: 777-779). 
La paz da paso a la inquietud por la llegada, dando cuenta del ya pero todavía no del Espíritu-Júbilo eterno que aspira a ambos a la intimidad bajo el signo de la cruz. Porque en definitiva, bien puede definirse a la nupcialidad como ese mutuo aspirarse, pascual, transformante, resucitante y redentor que incorpora en la liturgia eterna. El Cántico nuevo que descentra, por el cual se hospeda al Amado que está llegando, en gerundio, y se lo recibe en exacto y sincrónico éxodo de sí para habitarlo:

Sabes muy bien que estoy aspirando el Cántico nuevo. Y nadie ha podido aprenderlo salvo los 144000 rescatados del mundo. Aquellos que Dios hizo suyos, por Cristo, tienen como alma una melodía nueva, infusa, inalienable, naciente, auroral, filial.

Siguen al Cordero adonde vaya. [...] Esta noche, antes de empezar el oficio, Christian nos anuncia que Vivianne y Angela, dos de nuestras hermanas, han sido asesinadas el domingo por la tarde en Belcourt al salir de misa. Leo y releo el Apocalipsis. De camino, el lector. Sí, de Ti se trata, Cordero vencedor y degollado. De Ti que vienes pronto. Quisiera ser envuelto en tu Movimiento de VIDA entregada. Vivianne y Angela: Descubrimiento de Jesucristo entre nosotros. Ellas han sido testigos de tu testimonio (Lebreton, 2002: 225.227).

Bajo la espléndida figura del cántico / melodía nueva, vislumbramos la alegría propia de la alabanza-martirio, incoándose ella como versión existencializada de la pascua, de la muerte muerta. Un alegría-melodía que se muestra infusa, inalienable, naciente, auroral y filial según Lebreton. Y profundamente nupcial, agregamos sin retaceos. Una melodía que es «movimiento de vida entregada», tan litúrgica como el coro de los monasterios de Thibirine o de Echt, y tan sensible y eficaz como la entrega de sus cuerpos en Auschwitz o en Argelia.

Ambos redactan un Testamento en el que podemos reconocer la presencia de la alegría como signo de la nupcialidad en la tensión escatológica propuesta. El 9 de junio de 1939, E. Stein escribe: «Desde ahora acepto con alegría y con perfecta sumisión a su santa voluntad, la muerte que Dios me ha reservado» (Stein 2004d: 515). Por su parte, la clave nupcial es más evidente en el texto de Lebreton, quien en el mismo mes en que es secuestrado por los terroristas envía a un monje de otra comunidad el siguiente escrito:

Testamento

mi cuerpo es para la tierra

pero por favor

sin preservativo

entre ella y yo 
mi corazón es para la vida

pero por favor

sin formalidades

entre ella y yo

mis manos para el trabajo serán cruzadas

con toda simplicidad

pero el rostro

que permanezca al desnudo

para no impedir el beso

y a la mirada

Déjenla VER (Olivera, 2008: 198).

Desnudez de la muerte, visión del rostro de Dios, beso del amor que aspira hacia adentro del misterio trinitario: signos nupciales ya no vistos desde el origen sino desde el fin. La conciencia nítida y contundente de Amantes que se sabe atraídos irresistiblemente hacia el gozo de la entrega, pero en la espera solo se sostienen en la certeza de la Alegría venidera.

\section{Conclusión}

El diálogo entre dos que, mirando hacia la verdad que habita fuera, se descentran y se encuentran, ha demostrado ser, una vez más, camino fecundo para la investigación actual. La amplitud y hondura del fenómeno humano y su relación con lo divino requieren de perspectivas de análisis que en el intercambio recíproco encuentran su fuente de alimentación y crecimiento. La teología ha aceptado el desafío y la poesía ha demostrado ser su aliada también en el siglo XXI, aunque con nuevos modos. A la milenaria alianza entre místicos y vates, se viene así a sumar ahora la posibilidad de encontrarse los lenguajes de la rigurosidad y sistematicidad de las ciencias, las cuales cuando dejan de lado la pretensión de absolutez, pueden abrirse a la riqueza que provoca la complementariedad de enfoques y, como en este caso en particular, la de los «estilos teológicos» no convencionales.

Las notas de la nupcialidad recogidas desde la categoría de alegría afectada por su dimensión encarnada e histórica es el primero de los frutos recogidos en este diálogo. En esta misma línea, subrayamos también y en segundo lugar, que esta alegría es proporcional al grado de la compenetración con el Amado y que, por lo tanto, aumenta a medida que la «aspiración» hacia la entrega pascual se intensifica. Y así, en tercer lugar, concluimos en que el punto culminante de nuestra propuesta consiste en la emergencia teológico mística de la respiración o aspiración 
como uno de los principales aportes de este diálogo interdisciplinario, ya que en este dinamismo confluyen la figura poética en su dimensión estético teológica y la fuente trinitaria de la nupcialidad que aquí nos propusimos manifestar en el rostro de la Alegría.

\section{REFERENCIAS}

-Avenatti de Palumbo, C. (2006). Teología y Literatura. Lenguaje y acontecimiento. Teología (90), 365-371.

-Avenatti de Palumbo, C. (2010). Prolegómenos para el diálogo entre literatura, estética y teología. Belleza, herida y otredad como figuras de vida. En C. Avenatti de Palumbo \& J. Quelas (coord.), Belleza que hiere (págs. 17-39). Buenos Aires: Agape Libros.

-Balthasar, H. U. von (1985). Gloria. Una estética teológica. 1. La percepción de la forma. (E. Saura, Trad.) Madrid: Encuentro.

-Balthasar, H. U. von (1992). Teodrámática 2. Las personas del drama: El hombre en Dios (E. Bueno de la Fuente \& J. Camarero, Trad.) Madrid: Encuentro.

-Balthasar, H. U. von (2008). Consideraciones acerca del ámbito de la mística cristiana. En H. U. von Balthasar, A. M. Haas \& W. Beierwaltes, Mística, cuestiones fundamentales (A. Capboscq, Trad., págs. 45-78). Buenos Aires: Ágape Libros.

-Bertolini, A. (2013). Empatía y Trinidad en Edith Stein. Fenomenología, teología y ontología en clave relacional. Salamanca: Secretariado Trinitario.

-Bertolini, A. (2014). Un Dios empatizable y empatizante. Alteridad, cuerpo y martirio en la síntesis de Edith Stein. En F. J. Sancho Fermín (dir), La identidad de la mística: Fe y experiencia de Dios. Actas del Congreso Internacional de Mistica, Ávila 21-24 Abril 2014 [Homenaje a los 400 años de la Beatificación de Sta. Teresa de Jesús (págs. 465-483). Burgos: Monte Carmelo-CITeS - Universidad de la Mística.

-Juan de la Cruz (2004). Obras completas (Octava edición). Burgos: Monte Carmelo.

-Lebreton, C. (2002). El soplo del don. Diario del hermano Christophe, monje de Tibhirine, (S. F. Ordoñez - E. Antoine, Trads.) Burgos: Monte Carmelo.

-Olivera, B. (2008). Traje de bodas y Lámparas encendida. Espiritualidad y Mistica Esponsal: ¿caducada o vigente? Burgos: Monte Carmelo.

-Ricoeur, P. (2001). La metáfora nupcial. En A. Lacocque \& P.Ricoeur, Pensar la Biblia. Estudios exegéticos y bermenéuticos (A. Martínez Riu, Trad., págs. 275310). Barcelona: Herder.

-Stein, E. (2004a), Escritos espirituales (F. J. Sancho, J. Urkiza, Trads.) Burgos: Monte Carmelo - Espiritualidad -El Carmen.

-Stein, E. (2004b). Escritos filosóficos: etapa cristiana, (A. Pérez, J. Mardomingo, C. Ruiz Garrido, Trads.) Burgos: Monte Carmelo - Espiritualidad -El Carmen.

-Stein, E. (2004c). Escritos filosóficos: etapa fenomenológica (C. Ruiz Garrido, J. L. Caballero Bono, Trads.) Burgos: Monte Carmelo - Espiritualidad -El Carmen. 
-Stein, E. (2004d); Escritos autobiográficos y correspondencia (E. García Rojo, J. García Rojo, C. Ruiz-Garrido, F. J. Sancho, Trads.). Burgos: Monte Carmelo Espiritualidad-El Carmen.

Sumario: Introducción; 1. Nupcialidad como forma originaria del Amor; 2. La alegría como fruto de la fecundidad nupcial; 3. La alegría en tensión escatológica: contexto histórico y martirio; Conclusión; Referencias. 